\title{
Alles Metropolregionen?
}

\author{
Andreas Klee $\cdot$ Gregor Prinzensing
}

Online publiziert: 13. Juli 2010

(C) Springer-Verlag 2010

Der Begriff „Metropolregion“ macht schon seit einiger Zeit „Karriere“. Er hat Eingang in die Diskussionen um Raumstrukturen in Deutschland und Europa gefunden; und er hat vor allem auch im Kontext raumordnungspolitischer Strategien und Zielvorstellungen einen Platz zugewiesen bekommen. Ganz selbstverständlich sprechen heute Wissenschaftlerinnen und Wissenschaftler aus Kerndisziplinen der Raumwissenschaften und der räumlichen Planung von Metropolregionen oder gar Europäischen Metropolregionen, um einen bestimmten Grad an Größe, Zentralität und funktionaler Konzentration von und in Städten und Stadtregionen zum Ausdruck zu bringen.

Einen besonderen Bedeutungsschub erhielt die Debatte mit der Verabschiedung der neuen Leitbilder und Handlungsstrategien für die räumliche Entwicklung Deutschlands durch die Ministerkonferenz für Raumordnung im Jahre 2006. An anderer Stelle war daraufhin bereits vom „Metropolenfieber“ die Rede.

Der Begriff „Metropolregion“ hat aber auch in einem anderen Kontext inzwischen „Karriere“ gemacht. Er ist auch in der Alltagssprache und der Alltagswahrnehmung angekommen. Viele Akteure, jenseits aller raumordnungspolitischer Diskussionen, haben den Begriff in ihren Wortschatz und ihr tägliches Handeln übernommen - manchmal freilich mit anderen Begriffsinhalten.

Dr. A. Klee $(\bowtie)$

Akademie für Raumforschung und Landesplanung (ARL) -

Leibniz-Forum für Raumwissenschaften,

Hohenzollernstraße 11, 30161 Hannover, Deutschland

E-Mail: klee@arl-net.de

G. Prinzensing

Leibniz-Institut für Regionalentwicklung

und Strukturplanung (IRS), Flakenstraße 28-31,

15537 Erkner, Deutschland

E-Mail: prinzensing@irs-net.de
Der Ausdruck Metropolregion war ursprünglich eine eher informelle Begriffsbildung. Damit wurden eng miteinander verflochtene Regionen von einer gewissen Größe und überwiegend städtischem Charakter angesprochen. Heute werden darunter in erster Linie stark verdichtete Großstadtregionen verstanden, die für die gesellschaftliche, kulturelle und wirtschaftliche Entwicklung ihres Landes eine gewisse Bedeutung haben. Aus wissenschaftlicher Sicht sind aber nach wie vor viele damit zusammenhängende Fragen nicht ausreichend beantwortet. Sind Metropolregionen letztlich doch bloße „Raumordnungsrhetorik“, wie Hans H. Blotevogel bereits vor Jahren treffend fragte? Oder gibt es dafür eine empirische Referenz, gibt es für die Vokabel „Metropolregion" ein intersubjektiv nachvollziehbares gegenständliches Korrelat? Wie sehen das die maßgeblichen Akteure in den Metropolregionen? Und wie sehen sie sich selbst? Haben sie ein gemeinsames Selbstverständnis? Sollten sie eines haben? Und wie sollte eine funktional definierte Metropolregion räumlich abgegrenzt sein?

Im vorliegenden Heft von „Raumforschung und Raumordnung“" wird einigen dieser offenen Fragen genauer nachgegangen. Karsten Rusche und Christian Oberst wagen sich an eine regionalökonomische Evaluation des raumordnungspolitischen Konzeptes der Metropolregionen. Ausgehend von den elf „Europäischen Metropolregionen“ in Deutschland fragen sie, ob diese Räume der ihnen zugeschriebenen Rolle als Wachstumspole gerecht werden können. Können sie tatsächlich ausnahmslos als ,ökonomische Kraftzentren“ verstanden werden? Oder ist vielmehr - gleichsam im Diesseits der sportiven Metapher - bereits intern hinsichtlich der jeweiligen Teilregionen und deren funktionaler Ausrichtung zu differenzieren? Ein Befund der beiden Wissenschaftler sei vorweggenommen: die normative bzw. politische Bildung von Metropolregionen folgt nicht immer einer Logik ökonomischen Wachstums. Anders ausgedrückt: die Euro- 
päischen Metropolregionen in Deutschland sind nicht immer nach ökonomischen Verflechtungskriterien abgegrenzt.

Mit der Frage der Abgrenzung von Metropolregionen befassen sich auch Hans H. Blotevogel und Kati Schulze am Beispiel möglicher Metropolregionen an Rhein und Ruhr. „1 oder 2 oder 3?“ ist der Titel ihres Beitrags. Darin wird die Frage aufgeworfen, wie viele Metropolregionen an Rhein und Ruhr Sinn ergeben. Die Autoren liefern Anhaltspunkte dafür, welche raumstrukturellen Gegebenheiten - beispielsweise metropolitaneFunktionenundPendlerverflechtungenfür oder gegen spezifisch konstruierte Regionsbildungen sprechen.

Wir wünschen allen unseren Leserinnen und Lesern wie immer eine erkenntnisreiche und inspirierende Lektüre und allen an Metropolregionen Beteiligten eine erfolgreiche Kooperation. 